\title{
Application of Neuroscience on Architecture: The emergence of new trend of Neuroarchitecture
}

\author{
Mohammad Reza Maleki \\ Department of Architecture \\ Sanandaj Branch, Islamic Azad University \\ Sanandaj, Iran \\ Mr.maleki@iausdj.ac.ir
}

\author{
Qader Bayzidi \\ Department of Architecture \\ Sanandaj Branch, Islamic Azad University \\ Sanandaj, Iran \\ q_Bayzidi@srbiau.ac.ir
}

\begin{abstract}
Understanding and knowing neuroscience and its sub-branches applications as well as their interconnections has a significant effect on science development. Simoltaneous application of neurology, psychology and architecture gain a new trend named "Neuroarchitecture" or "basic nerve architecture". This paper tries to consider this new trend through qualitative research and descriptive analysis method based on library information analysis. In this way current paper firstly deals with this subject background and neuroscience definition and then refers to entry areas of this subject to other sciences. Then basic information related to human brain and measurement instruments of neurology science will be presented. This paper deals with neuroscience on economy, education, aesthetics, and environment psychology in architecture areas. At the end concluding discussion will be presented through analytic model of neuroscience influence on architecture
\end{abstract} (Neuroarchitecture) and its application method.

Keywords: Neuroscience, Psychology,

Neuroarchitecture, Architecture, Human Brain.

\section{INTRODUCTION}

We are witnessing significant growth of neuroscientists capabilities. These specialists directly investigate cerebral cortex activities on various time, places and frequencies. On the other hand integration of psychology and physiology leads to technique incorporation resulted to amazing progress of understanding brain activities and its different parts. Today many social sciences researchers use nervous imaging as a standard instrument or approach. This concept application reaches the peak when economy science begins to use nervous imaging techniques on its researches [1].

New method and combination of neurology with other fields has been developed after disappointing from traditional methods. Neuroarchitecture or basic nerve architecture is the result of integration of 3 fields of neurology, psychology and architecture which studies effective, sensitive, recognitive and affective reactions to environmental stimulus. Researches measures brain activities changes by using technologies like magnetic resonance imaging and eye tracking method and other ways to help us to understand effects of artifacts environments on human behavior in his surrounding effectively or which parts of brain involves in planning and creativity process.authors are encouraged to use referencing tools to automate the references and citations.

\section{RESEARCH PROCESS}

\subsection{Resarch questions}

1.what is neuroscience and what is its application in various fields of science?

2.what are measurement instruments and brain activities visualization?

3.what is neuroscience application on architecture(neuroarchitecture)?

\subsection{Research methods}

Research method of current paper is based on qualitative evaluation and descriptive analysis method as well as logical reasoning. It is based on studying and analyzing library information, their comparison and interpretation and conclusions. Qualitative research deals with interpreting conditions and emphasizing on researcher role as a vital element of research results [2]. This research allows researchers to interact with subject and use flexible ways to gather and analyze data, consider phenomena studied through a comprehensive view [3]. At first this paper considers "neurology science" background and its application, then it reviews human brain medical information and its specifications. In the following part it presents this science applied field in architecture.

\subsection{Literature review}

Neurology is the knowledge of studying fauna structures, functions, and nervous system which is on various levels from cellular and molecular to anatomy, behavioral science and medical pathology. Neurology is the translation of an English word neuroscience but this word usage in Persian is differed from English one. Neurology in Persian is the same as English word of neuroscience but neuroscience is referred instead of neurology.

Dr. Raymond Damadian performed the first M.R.I Scan with his group inventive tool in a small laboratory in Broklin of Newyork on 1977. I could observe alive brain activity without any harmful rays or toxic chemicals. And this is how neurology is created. The main purpose of neuroscience is to extract hidden information from 
individuals brain without using questions or questionnaire or interview but information is directly extracted. Several studies had been performed on the field of neurology and other fields during last years which mostly deals with training, educational science, marketing and medical topics. Mahmood Talkhabi (2012) studied difficulties and hopes of linking two field of neurology and education on his paper "alliance between neurology and education: challenges and hopes". He stated in concluding point that neuroscience give data as one of multiple approaches by which instructors can reinforce and justify their scientific views and thoughts. Mohammad Torabi name and Seyed Kamal Kharrazi (2012) studied the intersection of neuroscience, cognitive studies and medical education on their paper under the title of "neuroscience, cognitive studies, new ways of medical education". Firoozeh Asghari and Bahman Zandi (2012) on their paper "language neurology, interdisciplinary studies on linguistic" stated that studying this subject opens new gates of research for investigators about the first and second language learning biological foundations and on the other hand it plays a fundamental role on solving problems of thousands of patients suffering from dysphasia. Saman Shekh Esmaieli and etal (2013) on their paper "types of researching neurobiology marketing and its effects on marketing components" found that development of neurobiology marketing is significantly effective on understanding customers behaviors and could be effective on recognizing customers tastes, their expectations and motivations, behavior anticipation and justification of success or failure of marketing massages.

There is a few papers on architecture and neuroscience which did not directly consider this subject but refers to neuroscience through another major issue. One of these papers belongs to Seyed Amir saeed Mahmoodi (1998) under title of "training architecture a planning practice, using hidden talents of students". Author introduces a pattern on planning practice to utilize students talents with using two hemispheres of the brain characterizations. He studied the basic structure of planning and practices which could reinforce creative power though training these practices and applying students hidden talents.

Various foreign papers deal with applying neuroscience and architecture contrary of internal researches. This paper will refer to some of them.

\section{DISCUSSION}

\subsection{Neuroscience as an interdisciplinary studies}

An interdisciplinary area is integrating knowledge, methods and experiences of two or more scientific and expert area in order to understand and solve a complicated problem or multi facet social difficulties which is beyond the capacity and knowledge of one discipline or specialty. It is quoted from Klein and Newel that "interdisciplinary studies are process of answering to every problem, solving a problem or studying extensive categories or complicated ones which can not be solved based on solely on discipline or specialty"[4]. Neuroscience is recognized as one of the decisive and strategic sciences in future world. The importance of this interdisciplinary field is mostly due to its potential findings effects on other scientific areas and social fields. Eventually it will effect on all aspects of society life and welfare. During last two decades some fields as social sciences, education, laws, morality, art, philosophy, medical, technology and engineering and architecture has been benefitted from neuroscience achievements and even it is possible that current process of some fields face new challenges because of these findings. So necessity of training and investigating this subject is supposed as a national need. Hence architecture science takes advantage of other sciences achievements like every other sciences and in turn it has been applied on variety of areas. Table (1) briefly refers to the influence of neuroscience on other disciplines.

\subsection{Neurosciences}

This area studies the brain and its activities. Cognitive neuroscience is based on that mental activities derive from brain activities thus explaining cognitive processes require gathering information about brain while psychology considers mental incidences independent of brain activities. The purpose of cognitive neuroscience is to understand the nature and structure of mental activities. The approach of this science toward brain is a processing one. It means that mental activities are explained based on how to process the sub systems in which each of them is responsible of performing specific mental activities like reading a word or sentence, visual recognition of objects or humans, solving mathematics problems. These processor sub systems are explained based on brain activities patterns and brain structural information [5].

\subsubsection{The reason for suitability of neuroscience method on studying human behaviors}

Human brain is a precise and immediate predictor of his/her behavior.

About $95 \%$ of our decision happens on unconscious level or unconscious brain. Excitement is one of key stimulant of human behaviors. Studying excitement and its visualization on brain is easy but expressing excitement is difficult.

Human produce very lower added noise by comparing speech because of this it is more applicable. Since neuroscience directly deals with individual brain, it is a suitable method.

\subsubsection{Basic information in relation to human brain}

Only $2 \%$ of body weight is consisted of human brain and consumes $20 \%$ of oxygen and $25 \%$ of blood glucose.

Medium weight of brain of mature individual is $1 / 3$ to $1 / 4$ kilogram. Brain occupies about $80 \%$ of human skull and the rest is filled equally by blood and spinal fluid. Live brain tissue is semi-solid like toothpaste and consists of tangled deep grooves. This level is called brain membrane and houses 100 milliard neurons. 
Table 1: The main branches of neuroscience [6].

\begin{tabular}{|c|c|}
\hline Branch & Explanation \\
\hline Behavioral neuroscience & $\begin{array}{l}\text { Applying biology principles on study of genetic mechanism, physiology and behavioral } \\
\text { evolvement on human and animals }\end{array}$ \\
\hline Cellular neuroscience & Study of neurons on cellular level and their physiological characterizations \\
\hline Clinical neuroscience & Consisting expertise like neurology and psychology \\
\hline Cognitive neuroscience & Study of biological substrate, understand and emphasize on mental processing \\
\hline Computational neuroscience & $\begin{array}{l}\text { Study the brain from information processing view or to use computer stimulus or } \\
\text { hypothetical model to assess function of nervous system }\end{array}$ \\
\hline Cultural neuroscience & Study of how brain ,mind and genes shape cultural values, improve skills and beliefs \\
\hline Developmental neuroscience & Study of process of creating and forming and renovating nervous system \\
\hline Molecular neuroscience & $\begin{array}{l}\text { It is a branch of neuroscience which study biology of nervous system by using } \\
\text { molecular, genetical and related methods }\end{array}$ \\
\hline Neuroengineering & $\begin{array}{l}\text { It is a branch of biomedical engineering basics which is used to understand renovation } \\
\text { and replacement of nervous system }\end{array}$ \\
\hline Neuroimaging & Using various techniques to assess brain structure and to understand its activities \\
\hline Neuroinformatics & $\begin{array}{l}\text { It is one of the bioinformatic principles which relate nerves data structures with } \\
\text { computational models and analytical instruments }\end{array}$ \\
\hline Neurolinguistics & $\begin{array}{l}\text { Study of parts of the brain related to comprehension, creating and acquiring language on } \\
\text { human }\end{array}$ \\
\hline Neurophysiology & Study of nervous system using physiological principles \\
\hline Social neuroscience & $\begin{array}{l}\text { An interdisciplinary branch assesses biology principles, collective process and } \\
\text { behaviors including affective neuroscience branch }\end{array}$ \\
\hline Systems neuroscience & Nervous system science studies functions of neural circuits and systems \\
\hline Neuromarketing & Study of nervous system and its role on decision making for market \\
\hline neuroarchitecture & Study of planning environment effects on users of that environment \\
\hline
\end{tabular}

Human brain is divided into two parts based on one classification: unconscious and conscious. Professor Zaltman from Harvard university added new elements to Freuds hypothesis through enjoying his theory of unconscious mind. According to Zaltman interpretation, unconscious mind orders but conscious mind obeys. You make decision by your unconscious mind but conscious mind rationalize this decision. Indeed $95 \%$ of our decisions origins from unconscious mind and only $5 \%$ is from conscious one. Zaltman believes that research institution has reached to extempore layer or costumer/consumer reasoning by applying usual and customary questionnaire which is only $5 \%$ of the matter while 95\% are ignored. Psychologists use iceberg example in this regard. Usually we see a small part of iceberg but its huge part is under the water and we cannot see it. Conscious mind is the known part out of iceberg but unconscious mind is that huge part under the water (Figure 1).

A prominent psychologist Ned Hermann believes that mind consists of 3 layers including: 1-extempore layer 2wisdom layer 3-creativity layer. Extempore layer is the elementary and surface level and accessible part of mind. Wisdom layer is a logical, farsighted and computational part of the mind. If you ask someone to be present at the thought room in order to find a solution to a problem, then this part will be involved. Creative layer indeed begins with breaking paradigm. Main mechanism of creative layer is changing frameworks, breaking frameworks and connecting non-linkable topics to each other.

Researches performed in neuroscience show that brain consists of 3 different parts with distinct structures Figure 2) which each of them have a distinctive function and purpose, although these parts are in connection with each other and interact [7] :

1-lizard brain or cortex : its expertise is thinking. This part of brain processes the logical data and its inferences offers to other parts. Voluntary works, learning and logical decisions are performed by leadership of this part.

2- Mid brain : it is involved with memory and its duty is processing excitements and feelings and offers the result of its work to other parts.

3- Old brain or Reptilian brain: its duty is decision making. This part of brain deals with human survival and saving it. This part continues this duty for millions of years because of this it is so-called reptilian brain. 
Table 2: Old Brain Stimulants [11].

\begin{tabular}{|c|c|c|}
\hline Row & Old brain characterization & Explanation \\
\hline 1 & Agocentric & Old brain only tickling its survival selfishly \\
\hline 2 & Sensitive to conflict & $\begin{array}{l}\text { Old brain is aroused when something changes. This brain cannot decide } \\
\text { without conflict. Conflict is formed through two methods as good as } \\
\text { possible. } \\
\text { 1. story telling: old brain likes listening to story and a fabulous real story } \\
\text { can vary it. For example your solution story to solve a problem helps } \\
\text { audience to have a feeling that he needs the same solution and changes. } \\
\text { 2. visual tools: we only could remember } 10 \% \text { of what we hear verbally after } \\
\text { passing } 72 \text { hours but rate of remembering increases to more than } 65 \% \text { after } \\
\text { adding picture. }\end{array}$ \\
\hline 3 & Skeptic and incredulous & $\begin{array}{l}\text { The old brain has a skeptic and incredulous nature and helps us to continue } \\
\text { our life more than thousand years. It should be fed by tangible and objective } \\
\text { information. }\end{array}$ \\
\hline 4 & The importance of first and last & $\begin{array}{l}\text { Old brain is more alert automatically at the beginning and end of reaction. } \\
\text { Old brain is aroused in case of changing these conditions }\end{array}$ \\
\hline 5 & $\begin{array}{l}\text { The importance of sense of sight } \\
\text { and see pictures }\end{array}$ & $\begin{array}{l}\text { Vision nerve act } 25 \text { times faster than auditory nerves and they are directly } \\
\text { connected to brain. } 60 \% \text { to } 80 \% \text { of all transferred information to brain is } \\
\text { through vision pictures. New brain analyzes words but old brain analyzes } \\
\text { pictures. }\end{array}$ \\
\hline 6 & Thrilling & Old brain is aroused by excitement and feelings. Cares to the five senses \\
\hline 7 & $\begin{array}{l}\text { Gaining pleasure and peace, } \\
\text { avoiding pain and sadness }\end{array}$ & $\begin{array}{l}\text { Delicious foods, gas coolers, beautiful and expensive cars and... will not } \\
\text { being sold if it was not so. }\end{array}$ \\
\hline
\end{tabular}

Most of involuntary and basic decisions are made by old brain like breathing [8].

The most important point is that scientists concluded that most of human decisions are made by old brain. For example why people claim liking bitter coffee while drinking sweet coffee? The reason is that we usually use our new brain to answer while being questioned and we try to present the best and most logical possible answer. But our old brain has more influence on our performance when we are drinking coffee in real situation.

Neuroscience has shown that old brain could be aroused and by 7 stimulus and reacted to them which shortly are explained in table (2).

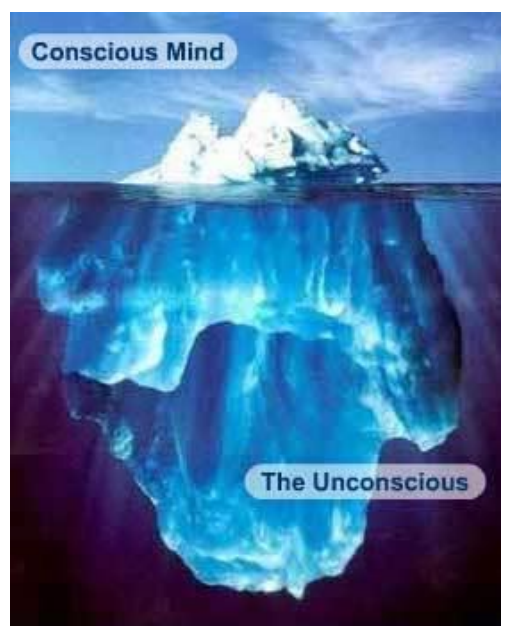

Figure 1: conscious and unconscious mind [9]. 


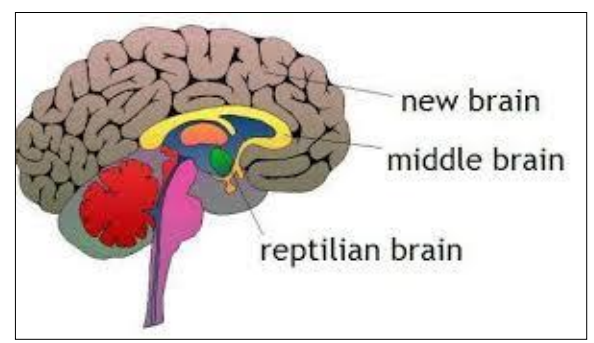

Figure 2: conscious and unconscious mind [10].

\subsubsection{Onboxing}

An expression which means taking pictures or recording a video of the stages and details of opening a product from the box and checking its accessories and the product itself is expanding rapidly. These films or photos are available to the public in a virtual environment. The popularity of this video is the product of mirror neurons. The attraction and effectiveness of Onboxing is the same; when you see that someone is doing something, you feel that you are doing the same action and enjoy a real action. The example of Onboxing in architecture is pictures and videos that a designer does by software such as 3DMax, Root and Rhino before making a project.

\subsubsection{Familiarity with brain mirror neurons}

Cells that are responsible for the biological foundation of cognitive responses are called neurons. In our brain, there are more than 100 milliard neurons and trillions of connections between neurons. Mirror neurons, as its name suggests, is a neuron that activates when a living creature performs an action or when it is seen that the action is done by the other one. Therefore, the mirror neuron reacts in the observer neuron in a way as though it were doing it by itself. Mirror neurons have necessary potential to understand behavior, imitative learning and the simulation of the behavior of other people. These neurons enable us to understand the thoughts and emotions of others (empathy).

\subsubsection{Neuroscience tools}

The six following methods are more reliable and secure than other methods for measuring and illustrating brain activities:

\section{FMRI: Functional Magnetic Resonance Imaging :}

Application imaging is related to brain magnetic resonance and is the brain's most advanced scan tool. This technique measures the magnetic properties of blood hemoglobin (a part of the red blood cell that is supposed to carry oxygen). In other words, it measures the amount of oxygen blood in the brain. When the brain carries out a special task, that part of the brain will need more fuel. The fuel of brain is oxygen and glucose. Hence, if a part of brain has more activity, it will also increase its fuel consumption and the oxygenated blood collection will illuminate in a red light in that part of the brain.

Investigating these interactions, neuroscientists realize which part of the brain is used at any given time. This method is 10 times more accurate than the ANSI device in location recognition, but it has less precision in time recognition and the activities of the brain cannot be investigated instantaneously in the millisecond.

EEG: Electroencephalography: electrodes on a person's head are investigated with the use of special warheads. Brain waves are recorded at very short intervals. Some new E.E.J's can record brain waves up to 10,000 times per second. In the E.E.J, the activity of the brain rest mode is recorded. Then the person is exposed to a stimulus or message. This situation causes changes in the electrical response of the brain. With comparing the electrical activity of the brain in both states, rest and duty (providing stimulant), we can investigate the specific function of brain in relation to the stimulus precisely. One of the limitations of electroencephalography is its inability to recognize the precise location of stimulation of neurons in the brain. This limitation, especially in the lower parts and old structures of the brain, is further enhanced due to the inability of the electrodes to capture electrical signals in the lower parts of the brain (Figure 3).

MEG: Magneto encephalography: like the E.E.J method, it is also limited to activities that are performed on the surface of the brain and cannot detect activities that are carried out inside the depth of brain. Although the use of this method is very expensive and has some limitations, few studies indicate relationship between specific frequencies with controllable cognitive functions such as object detection, evaluation of linguistic memory and recalling specific incidents. Since this method is costly, the best use is to measure activity in the locations that we know that these specific activities are processed in that location of the brain.

QEEG: Quantitative Electroencephalography: QEEG or quantitative electroencephalography is a kind of E.E.G that provides the quantitative analysis of waves. With this method, brain waves are recorded in different eye states closed or open, and in the time of doing cognitive tasks such as reading, and after complicated calculations are done, the activity of each wave is represented by a numerical value and also a colorful map. With studying these figures and their maps with a natural and reference model, it is possible to survey and study the function of the brain. The advantages of this method include lack of its negative effects (nonradiation, radioactive injection or other harmful methods) and the ability to check the function of the entire brain.

Facial Coding: facial decoding is a method that uses facial muscle changes to evaluate advertisements. Various studies have demonstrated that when frowning, smiling and other excitements, different types of facial muscles are activated. Therefore, knowing the composition of the different muscles of the face, instantly you can figure out what kind of emotion a person has; is he upset or happy? Does he feel hate or anger? In this way, WebCam registers the emotional responses of the image viewer through a computer when he or she is looking, and then it analyzes the unconscious and intricate emotional indexes to achieve a deeper 
understanding of the emotional involvement of an addressee.

Biometrics: the biometric systems use human biological and behavioral attributes to identify, and they can be further used as complementary to previous approaches such as E.E.G. There are two types of biometrics in biometric evaluation. A) Behavioral Techniques: In this method, one of behaviors of a person is analyzed, for example, an individual's analysis through signature. B) physical and physiological characteristics: It is often more precise analysis such as fingerprints and eye iris, thermal diagram of the face, heart rate variability (GSR), respiration rates, muscle tension, body temperature, Heart Rate Variability and ...

Zoravicki (2010), Kening et al. (2008) and Calvert et al. (2004) categorized the types of tools used in neuroscience researches into techniques that record metabolic activities. Moreover, tools that measure electrical activity in the brain can be observed in the Figure (4).

\subsection{The application of neurology in the architectural economy}

Neuroeconomy is the name of a new branch of knowledge, a point of intersection of psychology, economics and neuropsychology, and its purpose is to survey human economic decisions from the perspective of these sciences. In these matters, human behavior is evaluated under the category of benefits and profits, and their responses. In fact, Neuromarketing is the direct results of this field of knowledge [11]. Product designers try to understand customer preferences to design products that have the most attraction for the target market. It is clear that consumers are influenced by the society, culture and their basic expectations. Moreover, most of their unconscious attitudes are influenced by previous uses. The use of brain imaging techniques can enable product designers to recognize consumers' preferences and wishes and present more attractive products to the market [12]. According to Maureen (2011), the first experimental study of neuronal marketing was carried out in 2003 and it was published in the next year. In this experiment, a group of people drank Coca-Cola or Pepsi, and at the same time, their brain was scanned using a functional magnetic resonance imaging (FMRI), an appropriate methodology for discovering the active parts or regions of the brain. Finally, it was concluded that when people knew the brand of the product that they were consuming, the certain parts of their brains were activated whereas the certain parts of the brain would not be activated if they did not know it. According to this study, when people realized that they were consuming Coca-Cola, they said that they preferred Coca to Pepsi, and the anterior lobe of the brain was activated, an area that associates between attention and accuracy, controls short-term memory and coordinates thinking, especially planning. When people did not recognize the used brand, they reported that they preferred Pepsi and the structure of the system that was responsible for either emotional or instinctive behavior was activated. These findings showed that emotional stimuli or those product brands have an effect on the activity of the brain and consequently, on the manner of shopping behavior.

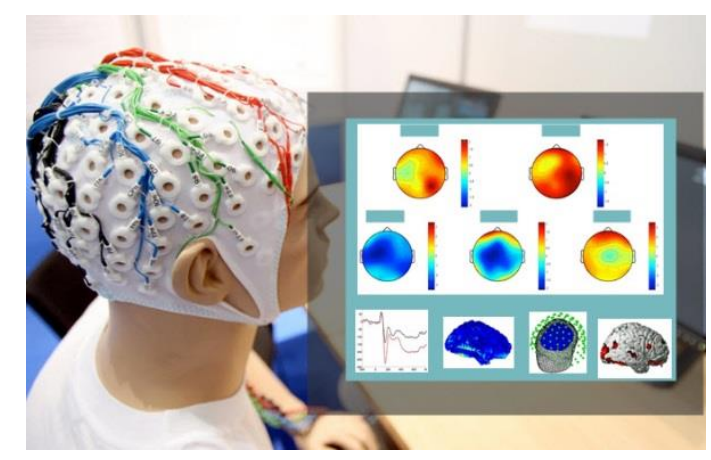

Figure 3: EEG [13].

It's the same in architecture, for example, when we put a nice architectural design drawn by a senior university student on a table and ask some architects to score this design that the name of university student is written on, the results of the grades will be completely different if the name of one of the contemporary architects is replaced by the name of the university student. It's the same psychological impact on decision making. It is possible to study and do research about how to present a design of architecture (Prasanth), how to express and defend the design, how to interact with an employer and many other matters whose results can be a new window in the architectural economy and marketing.

\subsection{Application of neurology in architecture education}

Design is a complex multifaceted process in which hands, eyes and mind collaborate together. Understanding specific cognitive processes and forms of knowledge used in creative ways is essential. Neuroscience provides valuable tools for thinking analysis and design processes that complement traditional design research. Neuroscience testing is for studying creative processes, visualization and learning skills in the fields of art and design. The purpose of this experiment is to identify the processes of design activity and the role and functions of the different areas of the brain at design time. Researches in the field of design show that in two broad areas, lack of studies is seen: 1) neurological research in design; and 2) empirical research in the aspects of design visualization.

Human brain is composed of two hemispheres that behavioral characteristics are derived from. Researchers in the sciences of neurology and psychiatry believe that the characteristics of two brain hemispheres are very different and consider human behavior as the result of referring to these hemispheres [15]. The two hemispheres of the brain can be seen in figure (1) and their characteristics can be known. As we can see, the right hemisphere of the brain can be described as a space hemisphere which deals with the matters of imaginations, emotions and space, and the left hemisphere is introduced as a verbal hemisphere which is more closely related to the matters of language, logic, and computations [16]. 


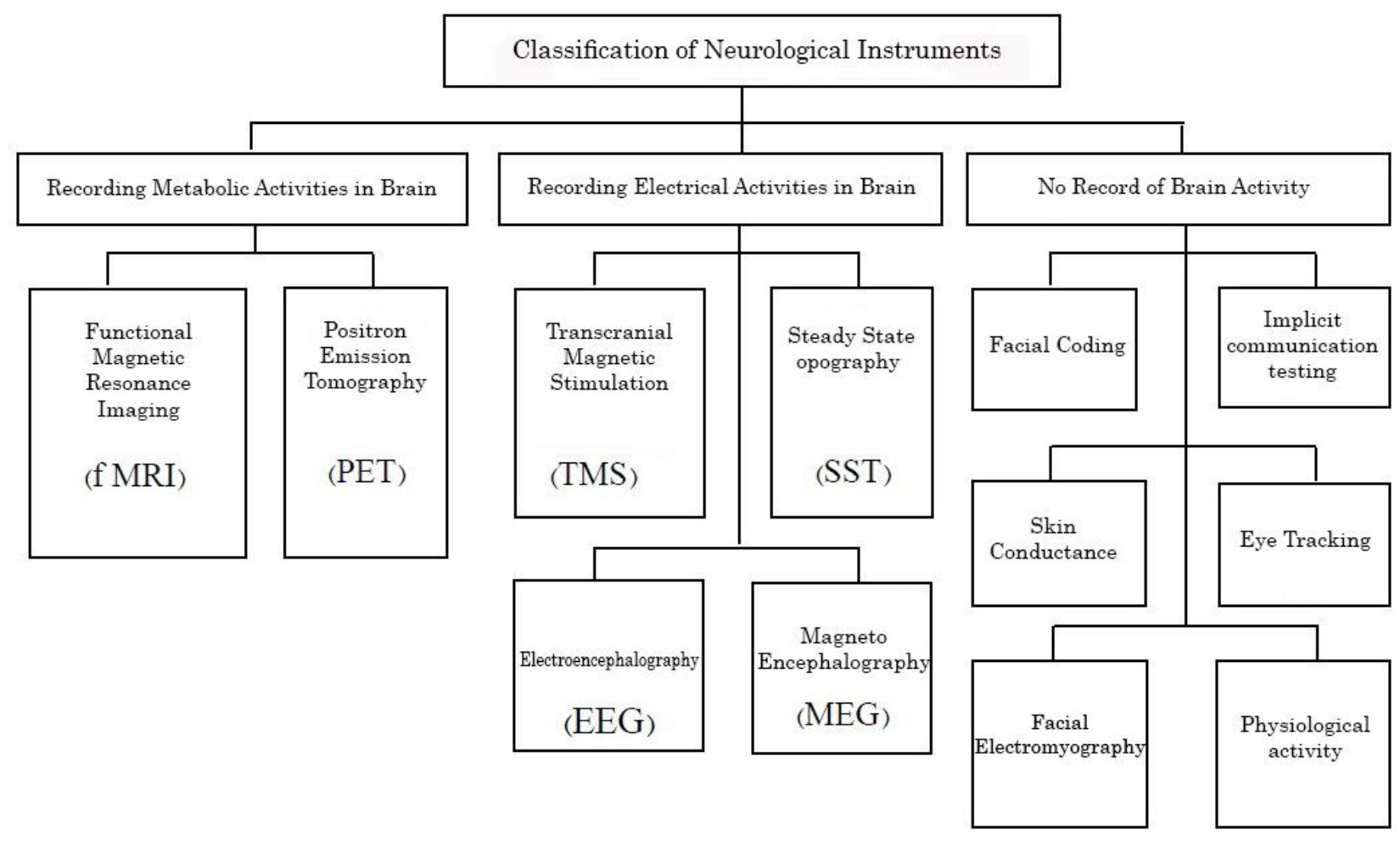

Figure 4: Classification of Neurological Instruments [14]

Most people rely on brain left hemispheric commands because it is possible to express words and remarks through the left hemisphere and to use it for rational thinking and reasoning in solving day-to-day problems [17].

In design, most of analyses and decisions are the result of using the left hemisphere. But paying attention to the characteristics of the right hemisphere of the brain which include spatial, non-verbal, and visual thinking, a person can use the hemisphere in the design process through employing hidden talents in the production of ideas and space imagination. The flourishing of hidden talents is possible through the appropriate and simultaneous application of the two brain hemispheres. The way of activation of both brain hemispheres during design process as a diagram of the information flow between them is introduced as simultaneous attention to design issues in the Figure (5). As it was already mentioned, in this interactive pattern, the studies and analyses that the left hemisphere usually carries out should coincide with visual studies and the use of other perceptions which are the functions of the right hemisphere of the brain. Finally, with the use of this template and the characteristics of both hemispheres, decision making about the major and minor aspects of a matter is accomplished and achieving to a unique and better answer becomes possible [18]. Figure (6).

\subsection{The application of neurology in architectural aesthetics}

Neurotic (neurological anesthetics) is a relatively new area in the cognitive sciences of nerves that includes neonatal aesthetic experience, especially in visual arts. Neurotic researches are done with the use of photographic techniques and neurophysiology such as M. R. I, the function F.M R. I and electroencephalography. Neuroscience has recently helped a lot in revealing aesthetic features. Science, art and creativity are not really clear in different people. Parallel studies on the characteristics of art and the principles of brain organization have been highlighted through neurotic studies. Beauty as a mental experience can be examined through comprehensive studies in the areas of neuroscience, psychology, humanities and cultural perspectives. In addition, there are undoubtedly other factors such as cultural foundation. In neuroscience, it is believed that art refers to divergent goals for problem solving [19]. An artist concentrates on ordinary events deeply every day and uses the abilities of the upper cortex, but ultimately what makes work artistic, apart from creativity, is an outlet from the emotional system at the bottom surface of the brain cortex. In fact, artists use the combined properties of visual features in order to produce aesthetic components [19]. Nowadays, the controversial matter of neurotic does not limit only to the areas of physiology, psychology and sociology [20]. 


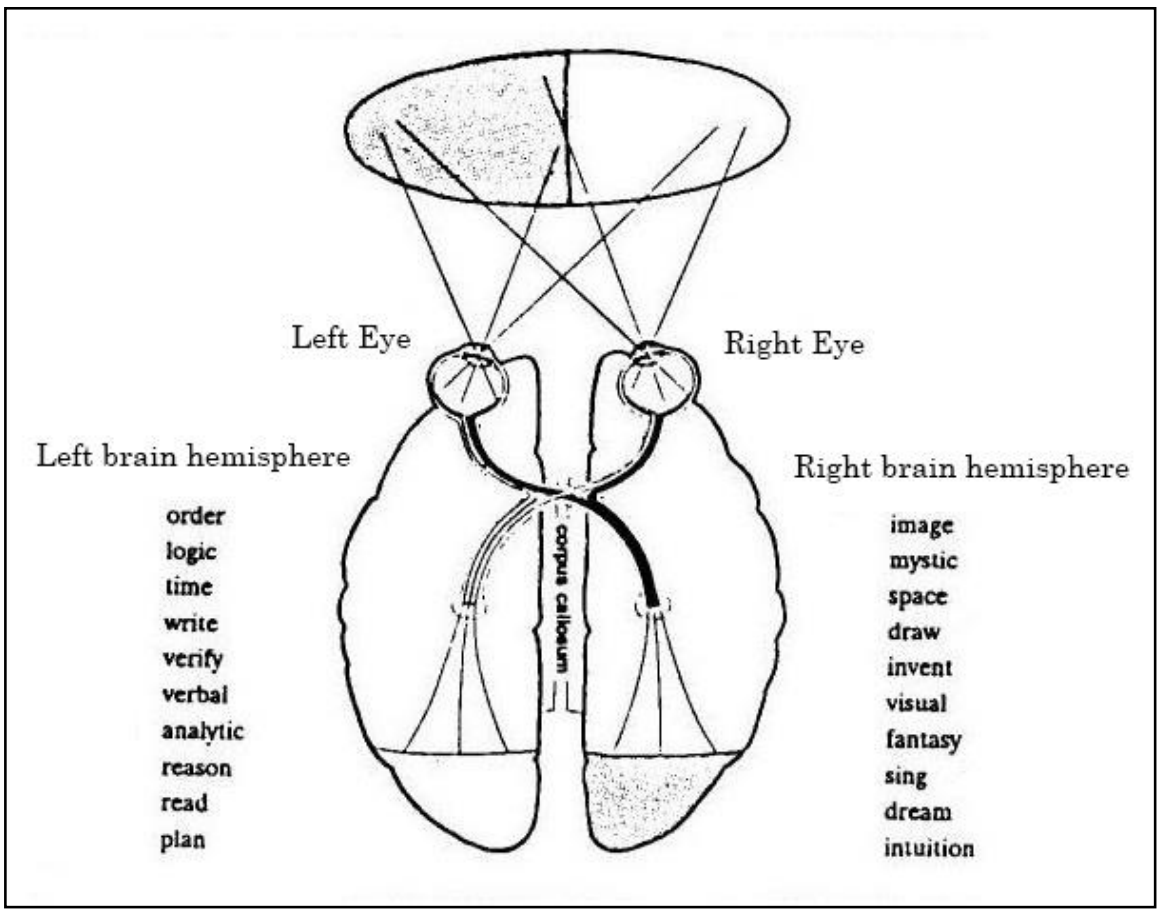

Figure 5: Characteristics of the Two Hemispheres of the Human Brain [18].

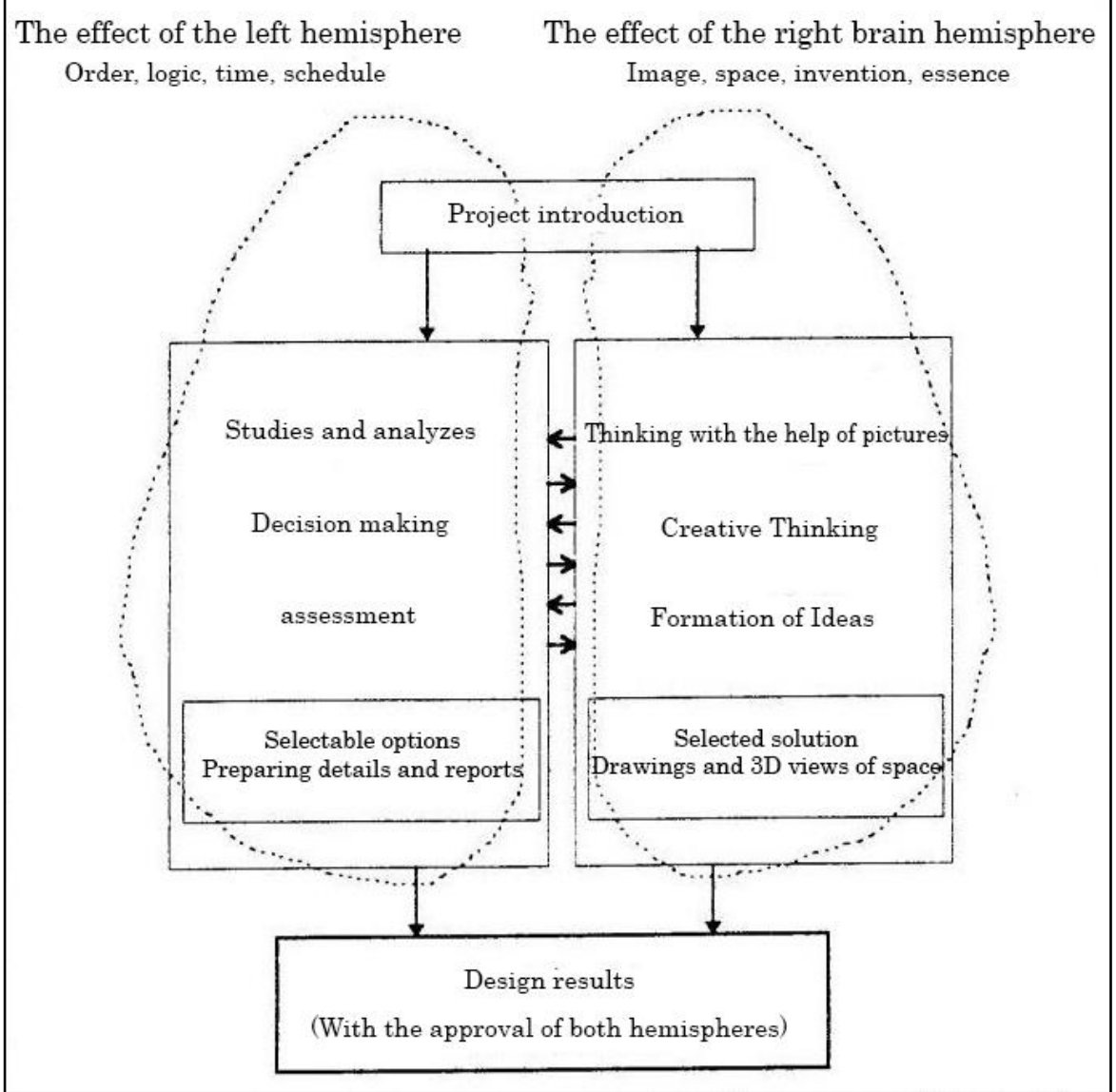

Figure 6: Introducing an Interactive Iattern in the Design Process for Using Latent Talent [18]. 
In two recent decades, scientific and experimental approaches related to neuroticism have been concentrated and focused by scientists. The analysis of quantitative and qualitative data extracted from brain, from the aspects of structure, programming and interpretation, leads to clearer insight about researches (neuropsychiatric) more than the emotional and logical features of this phenomenon. The present studies are useful through the analysis of different domains and research methods in cognitive neurosciences and they are not limited only to FMRI, ERP and transcranial magnetic stimulation [21]. The level of literacy, emotional intelligence, and specific social and cultural characteristics are potential confounding factors affecting the quality of the aesthetic perception of individuals in nerve studies The serious effect of the combination of emotions and the clear vision of the activity of the cerebral cortex has long been analyzed in the theories of Wittgenstein, Lukacs and Freud [22].

Neuroticism as a term developed by Zeki (1999) studies the neurotransmission of beauty perceptions in art. Neuroticism can be descriptive or empirical. Descriptive neuroticism is the study of the relationship between brain exercises and aesthetic experience. Data and results are categorized in qualitative type. In the experimental neuroticism, like other empirical sciences, the matters of the quantity and the production of data are considered. The method used by Zeki is to study the neuronal mechanism of brain response to art and consequently, the aesthetic experience of a complex subject. On the other hand, the results of neurological researches related to the perception of beauty are observed heterogeneously. Such a disagreement may be due to the absence of a consistent consensus in the definition of "aesthetic experience". Therefore, before empirical findings are analyzed, it is important to determine our intended aesthetics [23].. Insistence on the similar hypotheses of Zeki and its conceptual strength, the study of basic nerve mechanisms, the aid of the brain response to art, and the definition of aesthetic experience are considered as a complex problem [24]. An aesthetic experience is to allow a viewer to percept, touch and feel an art work and each one activates the emotional, dynamic and cognitive mechanisms in its own turn. The aesthetic experience of a visual artistic art with visual analysis begins with an actuator and then leads to levels beyond processing. This processing progress may lead to an aesthetic experience based on some of the biological and visual mechanisms that modify and change due to some factors such as subject, personal inclinations, awareness and prior knowledge and familiarity with the subject.

There is considerable disparity in the results of studies that have attempted to clarify neural connections in relation to beauty emotions. One of the reasons for these differences is the lack of consensus on the definition of aesthetic sense. Therefore, it is very important to refer to the definition of the concept of aesthetics before analyzing empirical findings, and then a criterion is considered to compare them. Some researchers have used the brain to study the psychology of aesthetics [25], and some have used beautiful objects to analyze the properties of the brain [26].
Feelings are different from the aspects of aesthetic experience and cognitive processes of rewarding in persons. This distinction means the concepts of beauty pleasure and evaluation that is related to the emotional and cognitive components of an aesthetic experience. In this study of neuroticism, participants are usually asked to have aesthetic evaluation about a visual stimulator and to judge it from the aspects of beauty and ugliness explicitly. Cavobatta and Zeki (2004) used the fMRI to study the nerve of communication in aesthetic perception and when various categories were observed from painting (landscapes, wildlife, portraiture, etc.), the responses of the participants (beautiful, Neutral or ugly) were recorded. The results of the nuclear imaging showed that stimulus was judged as beautiful, ugly and neutral, different activities were recorded in the orbitofrontal cavity of the brain (OFC). Orbitofrontal cortex (OFC) is the area of frontal lobe front cortex in the brain that involves in the cognitive process of decision making. The observed activities in the OFC decreased from baseline when people judged the ugly stimulant and in contrast, when the highest active level in the OFC was activated, the stimulant was beautifully judged.

In the study of Jacobsen et al., a study was done with the use of fMRI, the activity of the interstitial region was significant in the aesthetic experience [27]. In this study, participants were asked to evaluate abstract geometric shapes whose level of symmetry and complexity had been manipulated. It was observed that symmetry with stimulus complexity had affected aesthetic judgment significantly. The imaging results showed that there was a difference in comparison between the two modes. Activity in the involved areas in visual-motor processes, i.e., interplanetary groove and abdominal premolar cortex increased [28]. The beauty of the shown symmetrical patterns had been perceived more than their non-symmetrical ones. This was due to the continuous activities of the interplanetary groove for symmetry and beauty judgment [21]. This activity intensifies when people guess the intention of artistic activity or see the consequences of actions. The pleasure that people gain from looking at beautiful objects are automatically transferred to the brain reward system. For example, fascinating faces will activate areas in the brain, even without thinking about the charm of these faces. A similar answer to music and even architecture is seen. The role of expectations has also been studied in our enjoyment of artworks. People rated the abstract pictures that had the museum label more valuable than the similar pictures labeled by the computer. If It is imagined that a picture is labeled by the museum, it will make people consider it more luxurious. It is proved that even knowing the title of an artwork can deepen aesthetic experience. The originality of art works can have more effect than its copies on aesthetic pleasure. In fact, neural responses to the original and copies of the Rembrandt portraiture have been observed.

Neuroticism is in its early days. The concepts and priorities of this science are evolving. The scope of this science goes beyond the traditional notions of cognitive neuroscience such as perception, feeling, attention, conception, and decision making. The greatest challenge for neuroticism specialists is to overcome psychological 
inferences based solely on the location of neuronal activity. These results should be used as a production of neuroticism theories rather than validating a theory.

\subsection{Application of neurology in environment psychology}

Experiences are created through stimulation of the senses. These sensations send neural impulses among the nerves to the brain where they are decoded. The brain depends on several important chemicals that allow for decoding to occur in order to facilitate an emotional response. Among these chemicalsare the neurotransmitters including acetylcholine, dopamine, epinephrine, norepinephrine, and serotonin [29]. In order for a person to be mentally and in turn physically healthy, these neurotransmitters must remain in balance with one another. Imbalances may result in the development of psychological disorders. Medicine is typically prescribed to help regain balance and decrease effects of the diseases. Synthetic stimulants, however, tend to lose of effectiveness over time causing only a temporary change[30]. This is because they function as dopamine agonists, "mimicking the action of dopamine rather than replenishing the inadequate supply." [31]

Experience caused by the physical environment can also lead to an alteration in the production of each neurotransmitter through natural stimulation. While one is a substance that triggers a euphoric reaction synthetically, the other allows for the body to naturally "engineer" this euphoric feeling "through exposure of images and activities that stimulate a strong emotional response." [32]

Due to the differences in our genetic makeup, this strong emotional response can be achieved in quiet opposing ways. Dr. Marvin Zuckerman argues that these emotional responses as well as our behavior are dependent on a sensationseeking trait. Writing over 200 articles and book chapters [33]. Zuckerman contends that this trait is defined by the "seeking of varied, novel, complex, and intense sensations and experiences, and the willingness to take physical, social, legal, and financials risks for the sake of such experiences." [34] In his article, Sensation Seeking in England and America: Cross-cultural, age, and sex comparisons, [35] he argues that it can be measured and scaled based on a person's reaction to risk. While Zuckerman Sensation Seeking Scale (SSS) is heavily reliant on the participant's response to a question, psychopharmacological studies were done in attempt to find a biological explanation for the differences between low and high sensation seekers. It was concluded that dopamine, the neurotransmitter associated with the pleasure system of the brain as well as enjoyment and motivation, is strongly correlated to the SS trait [36]. Depending on the classification of personality type, low sensation vs high sensation, particular experiences lead to the increase in dopamine to reach a "mental high". For HSS, thrilling experiences lead to pleasure due to them being able to handle the high levels of stimulation and risk, while for LSS, these experiences lead to anxiety. LSS find pleasure in experiences that are stress reducing, while HSS find these places to be boring due to the lack of stimulation [37]. Evolutionary speaking, both of these personality types are necessary. "In a diverse society, you need both types," Zuckerman says. "You need people to keep the books and make laws and have families, and you need your adventurers like Columbus to explore and find excitement." [38]
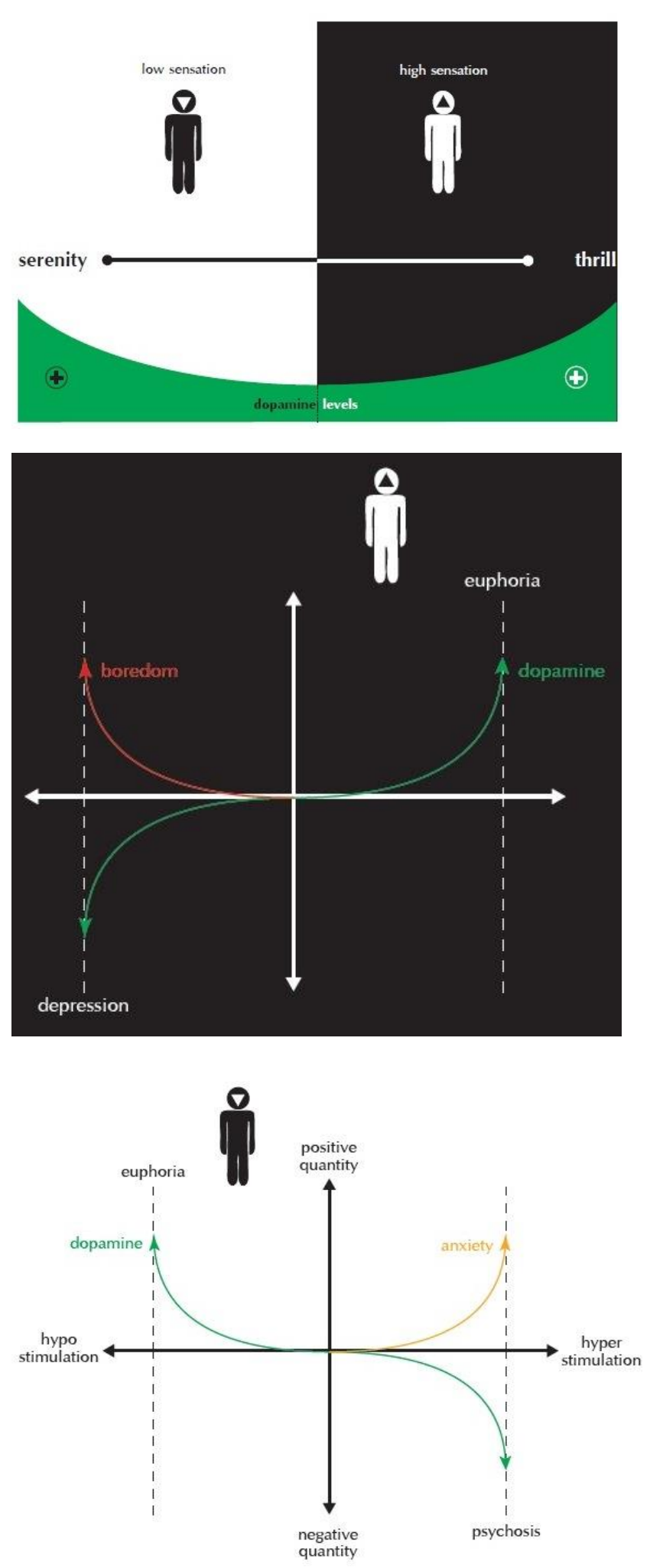

Figure 7: Genetic Differences of Humans [43]. 
Roger Ulrich is also responsible for defining the field of evidence-based design (EBD), "the deliberate attempt to base health care building design decisions on best available evidence." [39] This evidence is based off of the studies done such as his own as well as ones conducted during the Woods Hole Conference. In addition, research conducted by environmental psychologists have also aided in the delineation of 3 main principles of stress reduction: social support, control, and the integration of nature into the design [40]. EBD has become very popular in the healthcare design field in the last decade. By putting the focus on the experience of the patient, architects are able to decrease their stress levels. This decrease in stress allows the body's immune system to feel a sense of euphoria due to the dopamine increase. Triggering the emotional centers, nerve chemicals and hormones are released that alter how the immune cells fight disease.

Glaciar Skywalk, This arch pathway is situated on a cliff edge in Jasper, Canada. Offering a breathtaking view of the surrounding landscape, the Glaciar Skywalk, is described to be equivalent to "a rollercoaster in the park." Lofted 918 feet in the air, the visitor receives a rush of adrenaline when they transition from the thick steel structure to the thin glass membrane, creating a "strange sensations that you're practically standing on air." [41]

Amusement Parks, The thrill of the extremes brings many HSS to locations like this. Brightly colored rides, with continuous looping structures stimulate visually. Rides use elements of scale as well as sudden change such as giant drops to create an adrenaline rush. Not only is the experience of dropping at great speeds fear inducing, but the small compressive carts tied with the idea that you cannot escape until completion also elicits fear.

Paimio Sanatoriums, Designed by Alvar Aalto, this project integrates nature and architecture in order to 11 chievi a healing effect. Light was a central aspect to the project due to the contention, which was later proven, that light aids with healing. The site and material were both crucial in 11 chieving this tranquil effect. Soothing colors were also to ease the strain and further relax tuberculosis patients [42].

Vals Spa, Located in the mountains of Switzerland, this design strives to connect architecture with the site as well as create relaxing effects through the interplay of dark vs light, open vs closed space. The flowing circulation allows one to move from exterior space to the inside with ease.

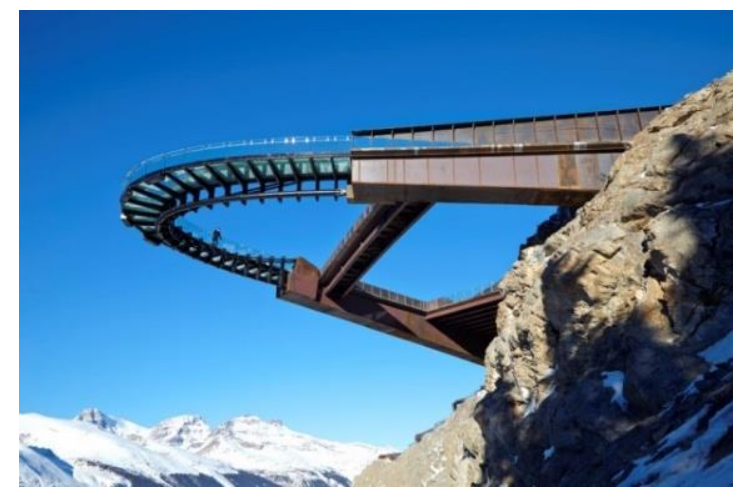

Figure 8: Glaciar Skywalk.

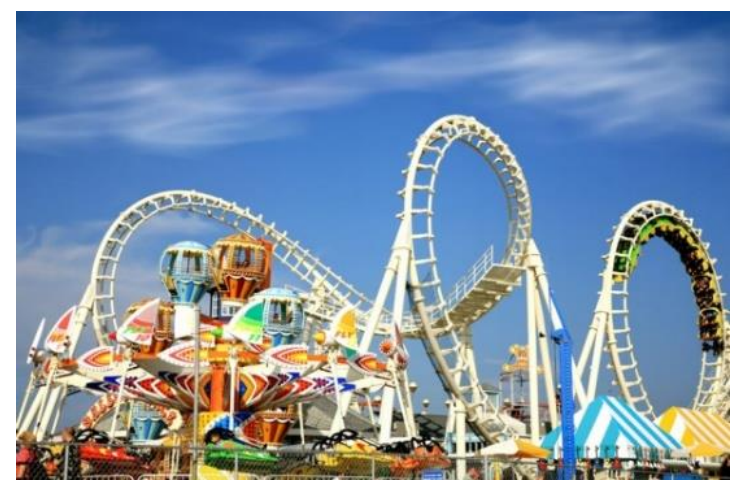

Figure 9: Amusement Parks.

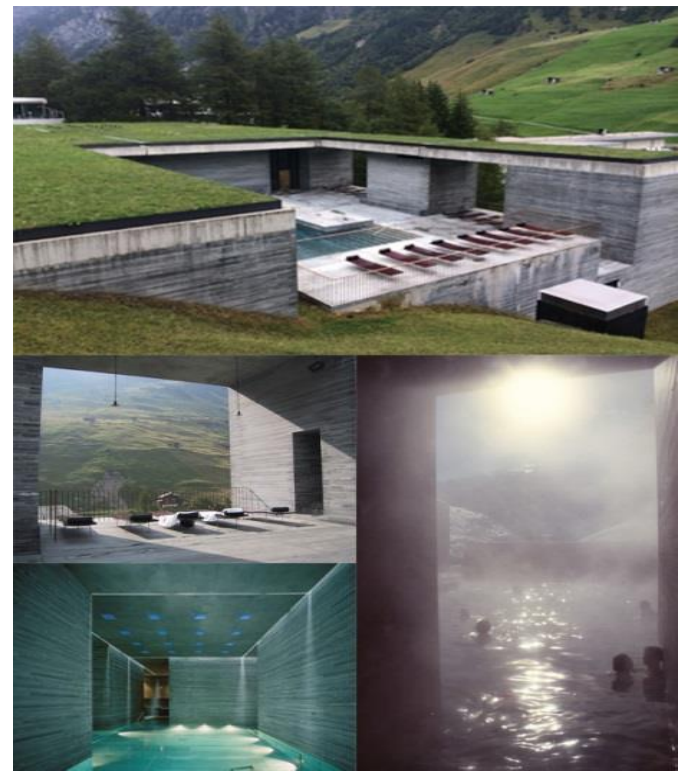

Figure 10: Therme Vals. 


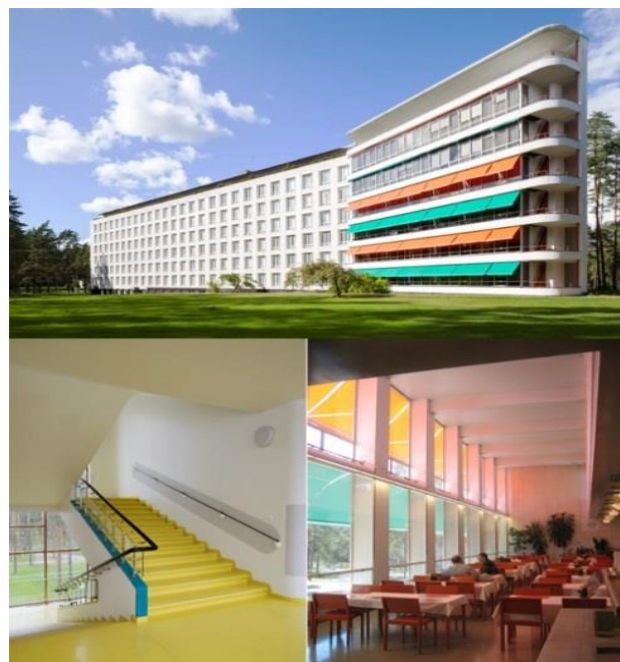

Figure 11: Paimio Sanatorium.

\section{Conclusion}

At the present time, the traditional techniques of research methodology such as questionnaires, scrolling and survey forms are less used. Many researches use penetrating techniques in the depths of the minds of individuals so that they can achieve to realities and can reduce error rates as much as possible. The purpose of this paper is to depict a clear and comprehensive picture of neuroscience, as well as to demonstrate the practical and empirical aspects of the tools of this science in the field of architecture. A better understanding of neuroarchitecture (neurological architecture) may increase our knowledge of the basic concepts related to human and the environment. In the Figure 12, the neuroarchitecture is shown as an interdisciplinary orientation and the scientific fields of its subset. Figure 13, the areas of application of neuroarchitecture as a particular orientation and in architecture as general orientation have been specified.

In spite of implicit utility, neurological architecture (neuroarchitecure) is still in its early stages, and many studies and researches have to be done in this regard. In spite of the growth of its concepts, there are still many questions and ambiguities in the use of its concepts and tools. This paper explains about this method and its applications in architecture apart from the literature review, definitions and tools. It is hoped that this article has been able to solve a small part of the study vacuum in this area and to give some solutions in its practical application and implementation.

Figure 12: Neuroarchitecture as an interdisciplinary orientation and the disciplines of its subcategories.

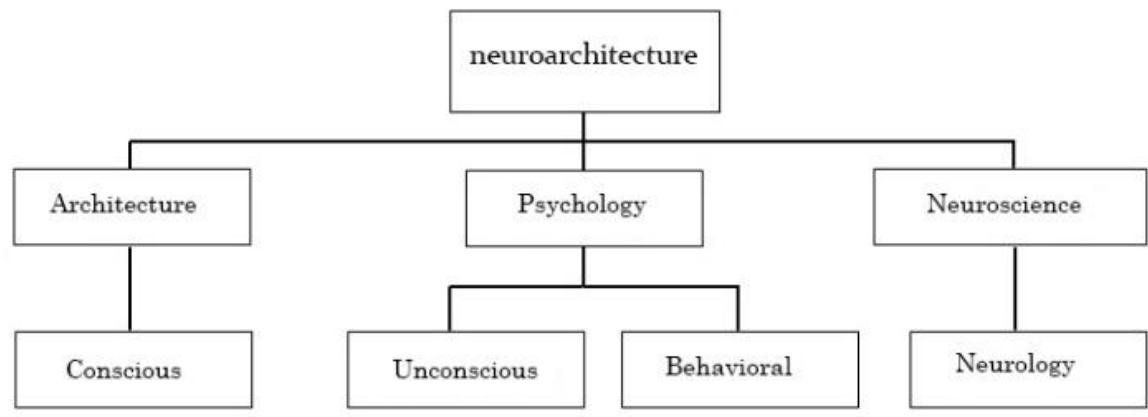

Figure 13: Areas of use neuroarchtecture.

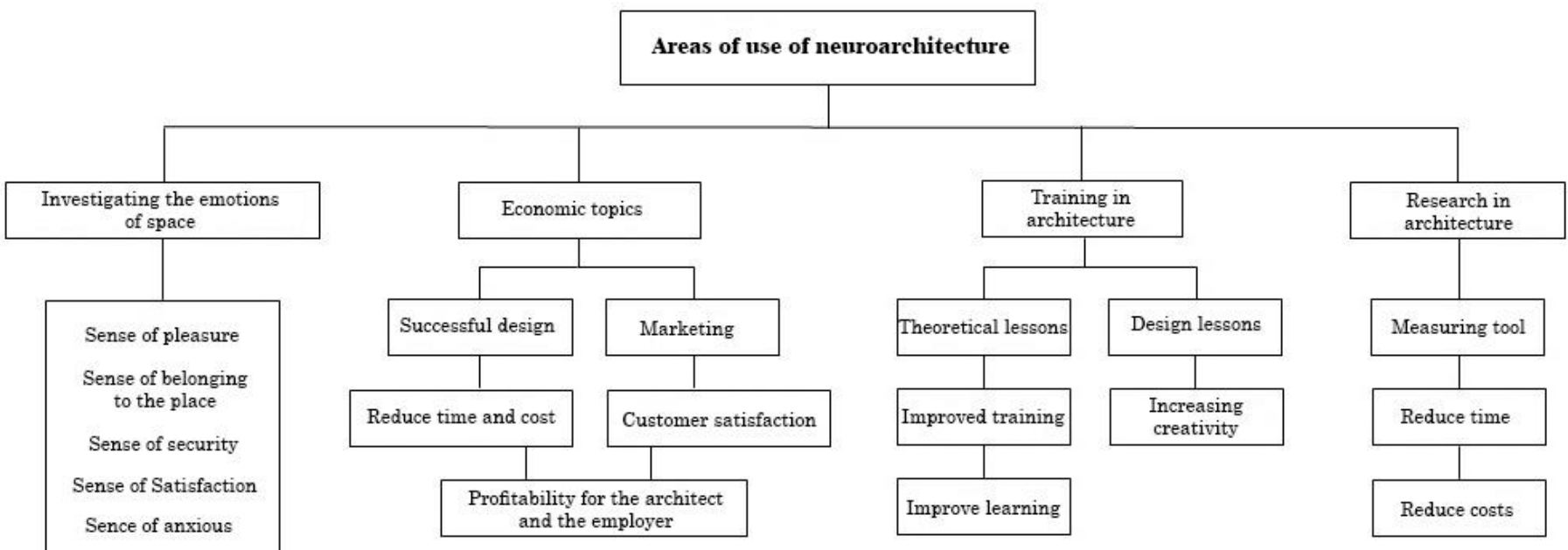




\section{REFERENCE}

[1] P. H, Kenning, \& H. Plassmann,. "How neuroscience can inform consumer research. Neural Systems and Rehabilitation Engineering", IEEE Transactions on, 16(6), 532-538, 2008.

[2] L. Groat. D. Wang, Architectural Ressearch Methods, Translation by Ali Reza Einifar, Tehran: Tehran University Press, 2002.

[3] N. Hriri, Principles and methods of qualitative research, Tehran: Islamic Azad University, Science Research Branch, 2011.

[4] J. Tofighi, H. Javdani., "Concepts, approaches, paleontology and typology, Quarterly Journal of Interdisciplinary Studies in Humanities", No. 1, 2008.

[5] M. Broon, "Cognitive Science, Understanding what's going on in the brain world, Biotech Monthly, Tehran University of Medical Sciences, No. 5, pp. 22-16, 2016.

[6] U. Goswami, "Neuroscience, education and special education". Br J of Spec Educ 31 (4): 175-183. doi:10.1111/j.0952-3383.2004.0035, 2004.

[7] K. Moore, "Maybe it is like brain surgery. Marketing"; 12: 110-15, 2005

[8] A. Peel, "Mapping the mind for the modern market researcher"; Qual Market Res Int J.; 2(10): 153-67, 2007.

[9] www.simplypsychology.org

[10] httpssocial-brain.com

[11] P. Dragi, Neuromarketing, theory and application, 2014.

[12] LD. Fugate, “Neuromarketing: a layman's look at neuroscience and its potential application to marketing practice", J Consum Mark, 24(7): 38594, 2007.

[13] alibaba.com

[14] S. Sheikh Esmaeeli, o. Seif, A. moradi, Types of neurological marketing research and its effects on marketing components", 2014.

[15] Sperry. R.W. (1985). Consciousness. Personal Identityand the Divided Brain. Guilford Prss.

[16] O. Faruque, Graphic Communication as a Design Tool. Van Nostrand Reinhold. NY, 1984.

[17] S.L. Diamond, Hemisphere Function in the Human Brain. Paul Ele, 1974.

[18] S.A.S. Mahmoudi, "Training in the design of architecture, the use of student latent talent", j Fine Arts, No. 4 \& 5, pp. 81-73. 1998.

[19] S. Zeki, "Art and the brain. J Conscious Stud: Controvers Sci Humanit”, 6,76-9, 1999.
[20] D.W. Zaidel, Neuropsychology of Art; Brain damage, behavior and cognitive series: psychology pre, 2005.

[21] A.Chatterjee,. "Neuroaesthetics: a coming of age story". J Cogn Neurosci,23(1),53-6, 2011.

[22] G.C. Cupchik,, La szlo, J. Emerging Visions of the Aesthetic Process Psychology Semiology and Philosophy:Cambridge University Press, 1992.

[23] H.M. Hoseinzadeh, M. Azamzadeh, "A Neuroaesthetics Revolution in the Perception of Art”, J New Neuroscience, No. 5, pp. 69-66, 2015.

[24] M. Torabi, S.K. Kharazi, "Neuroscience, Cognitive Studies, and New Methods of Medical Education", Quarterly Journal of Cognitive Science, Vol. 3, No. 2, Pages 34-24, 2012.

[25]H. Kawabata, S. Zeki, "Neural correlates of beauty", J Neurophysiol, 91,1699-1705, 2004.

[26]Zaidel, D.W. Neuropsychology of Art; Brain damage, behavior and cognitive series: psychology press, 2005.

[27] C. Di Dio, E. Macaluso, G. Rizzolatti, "The golden beauty: brain response to classical and renaissance sculptures". PLoS ONE, 11,1201, 2007.

[28] P. Locher, , E.A. Krupinski, C. Mello-Thoms, , C.F. Nodine, Visual interest in pictorial art during an aesthetic experience. Spat Vis, 21(1-2),55-7, 2007.

[29] D. A. Kopec, Environmental Psychology for Design. New York: Fairchild, 2006.

[30] "Parkinson's Disease" University of Maryland Medical Center. Available: http://umm.edu/health/medical/reports/articles/par kinsons-disease. [Accessed December. 2, 2014].

[31] "Dopamine Agonists." EPDA. Available: http://www.epda.eu.com/en/parkinsons/medinfo/d opamine-agonists/. [Accessed December. 3, 2014].

[32] "Addiction and Type-T Personality: Addicted to Horror." Health Guidance. Available: http://www.healthguidance.org/entry/16460/1/Ad diction-and-Type-TPersonality-Addicted-toHorror.html. [Accessed December. 8, 2014].

[33] M. Zuckerman, "Big Think", Available:http://bigthink.com/experts/marvinzuck erman. [Accessed December. 1, 2014].

[34] M. Zuckerman, "Behavioral Expressions and Biosocial Bases of Sensation Seeking", Cambridge: Cambridge University Press, 1994.

[35] M. Zuckerman, B. Sybil, Eysenck, and H. J. Eysenck. "Sensation Seeking In England And America: Cross-cultural, Age, And Sex Comparisons." Journal of Consulting and Clinical Psychology: 139-49.

[36] "The Journal of Neuroscience Society." Dopamine Modulates Risk-Taking as a Function 
of Baseline Sensation-Seeking Trait. Available:http://www.jneurosci.org/content/33/32 /12982.full. [Accessed December. 3, 2014].

[37] "Addiction and Type-T Personality: Addicted to Horror."http://www.healthguidance.org/entry/164 60/1/Addiction-and-Type-T-PersonalityAddicted-to-Horror.html.

[38] Munsey, Christopher. "Frisky, But More Risky." American Psychological Association. Available:http://www.apa.org/monitor/julaug06/f risky.asp. [Accessed December. 8, 2014].

[39] K. Weinstein, Bette. "Evidence Based Design: A New Concept in Health Care Facilities That Puts the Focus on Patients." ONA. September 25, 2014.

Available:http://www.oncologynurseadvisor.com/ evidence-based-design-a-new-concept-in-healthcare-facilities-that-puts-the-focus-onpatients/article/373488/.

[Accessed December. 1, 2014].

[40] "Designing Health Care Environments: Part I. Basic Concepts, Principles, and Issues Related to Evidence-based Design." National Center for Biotechnology Information. Available: http://www.ncbi.nlm.nih.gov/pubmed/19639918.

[Accessed December. 2, 2014].

[41] "Incredible Thrill and Adventure in Jasper with New Glacier Skywalk - Clapway." Clapway. July 11, 2014. [Online]. Available:http://clapway.com/2014/07/11/incredi ble-thrill-and-adventure-in-jasper-with-newglacier-skywalk/.[Accessed December. 28, 2014].

[42] L. Mindel, "Lee F. Mindel Travels to Finland's Paimio Sanatorium." Architectural Digest. Available:http://www.architecturaldigest.com/blo gs/architectseye/2013/06/paimio-sanatoriumalvar-aalto-architecture-visit-finland-blog.

[Accessed December. 1, 2014].

[43] R. Lovtcheva, Hedonic Architecture: Coexistance of Hyper Stimulating and Hypo Stimulating Experiences, Architecture Thesis Prep, School of Architecture Dissertations and Theses. 2014. Available: https://surface.syr.edu/architecture_tpreps/254. [Accessed July. 1, 2014].

\section{Biography}

Qader Bayzidi: Ph.D. in Architecture from Science and Research Branch of Islamic Azad University, Tehran, Iran in 2013. Dr. Bayzidi joined the faculty of Architecture at Sanandaj Branch of Islamic Azad University in 2002 and has also cooperated with University of Kurdistan since 2002. Holding the position of Assistant Professor, he is head of department of architecture from 2009 to now, as well as department of urban design \& planning since 2016. His teaching \& research interests include the dual concept of globalization and regionalism in contemporary architecture, the relationship between culture and architecture, contextual architecture, theories and manifestoes of architecture, identity \& sense of place, methods of architectural education, methods of architectural design, and urban renovation. He published ten journal papers and more than 50 conference papers. Accordingly, he participated as a member of scientific and judgement board in several international conferences and competitionson architecture. Dr. Bayzidi is supervising sixteen M.Arch. and five Ph.D.

Mohammad Reza Maleki: Ph.D. student of architecture, Department of Architecture, Sanandaj Branch, Islamic Azad University, Sanandaj, Iran. Faculty Member of Urban and Rural Development Institute BINAS. Board Member of MAVA Consulting Engineers. His teaching \& research interests include identity and sense of place, methods of architectural education, architectural design methods, Residential Architecture, neuroarchitecture, and Phenomenology. He published six journal papers and more than 25 conference papers. 